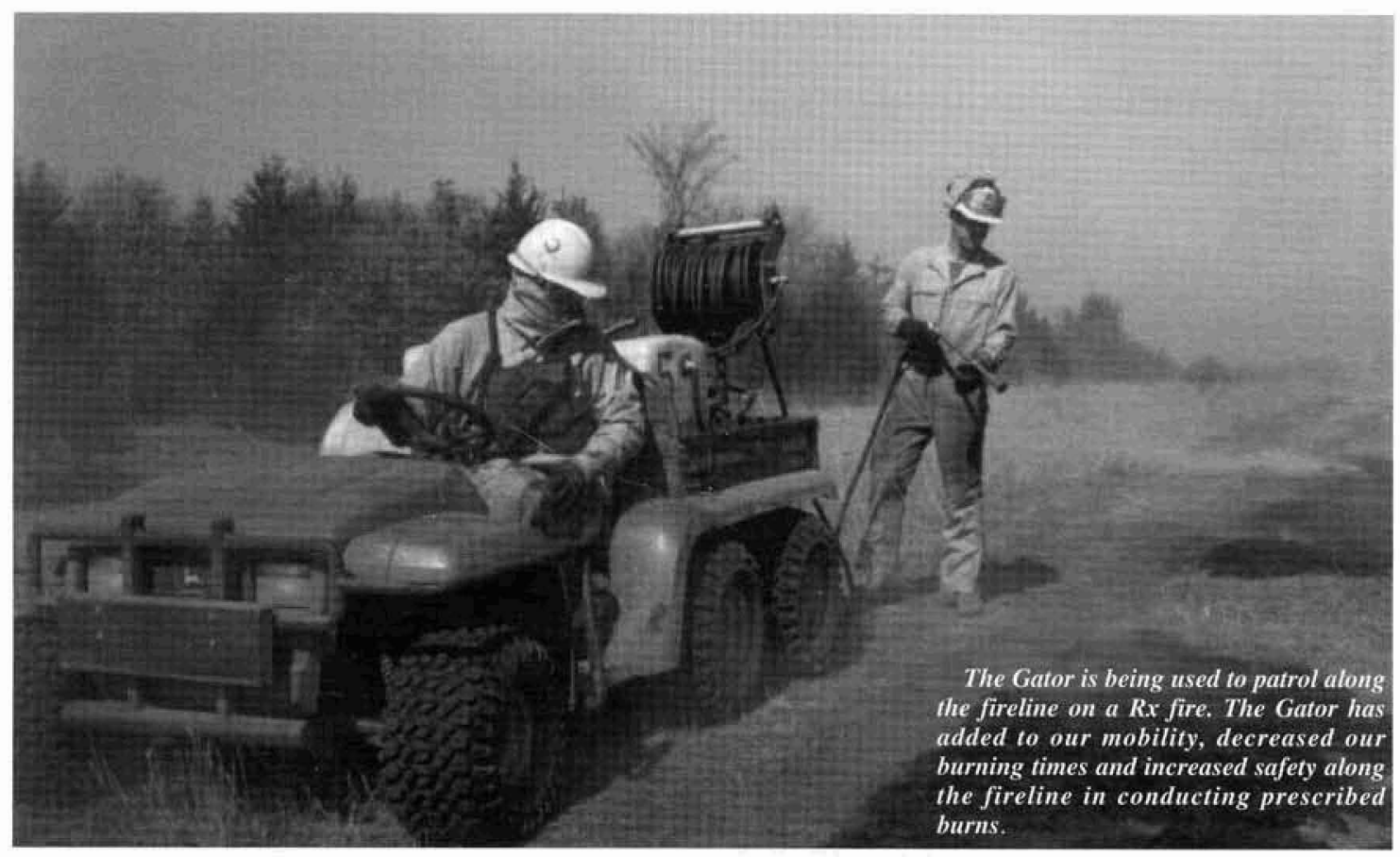

\title{
A Gator ${ }^{\mathrm{TM}}$ for Rx Fire
}

\author{
John R. Weir
}

A small and maneuverable vehicle is required to conduct prescribed burns on our research areas. Our prescribed burns vary from small plots that are $10-\mathrm{ft} \times 10-\mathrm{ft}$. to units several hundred acres in size. Most of our prescribed burning is done on the OSU Research Range (OSURR) in western Payne County, Oklahoma. This is in the cross timbers vegetation type, an area comprised of post-oak and blackjack-oak forest, and tallgrass prairie. Occasionally prescribed burns are conducted in the pines, and mountains of southeastern Oklahoma, or the rolling red prairies and shortgrass, of western Oklahoma. So the vehicle must also be able to transport with ease. We have been searching for a fire vehicle that has the ability to maneuver in tight quarters, carry a payload, operate easily, and handle terrain ranging from level ground to steep slopes and wet soil conditions.

The use of an All Terrain Vehicle (ATV) was our first thought, but with limited payload and restricted to no passengers, we thought it impractical. Our choice was the John Deere Gator ${ }^{\mathrm{TM}} 4 \times 6$ utility vehicle. We purchased the gasoline engine $4 \times 6$ utility vehicle with optional heavy-duty shocks, bed liner, and heavy-duty all purpose tires. The utility vehicle is equipped with an $18.0 \mathrm{hp}$ liquid cooled gasoline engine that drives a belt-driven torque converter, with a gear-driven transaxle. It has a single forward and reverse gear that allows the vehicle to travel up to $15.5 \mathrm{mph}$ in forward and 15.3 mph in reverse. The dimensions are 60.0 in. overall width and
106.0 in. overall length. It allows for a driver and one passenger in the front. It has a 42.5 -in. by 48.5 in. cargo box with an $800 \mathrm{lb}$. capacity.

We manufactured and added to our Gator a bumper, brush guard and front fender guards, which were heavier than those offered by the manufacturer, and we fabricated a slip-on pump unit for the cargo box. A manufactured slip-on fire suppression unit for the Gator is available, but due to price and parts on hand, we developed our own. A frame was made that fits the inside dimensions of the cargo box. Then to this frame we mounted a 55 gal. polyethylene tank, with a six roller, scoop rotor design pump, powered by a $3 \mathrm{hp}$ gasoline engine. A manual hose reel was added that holds $100 \mathrm{ft}$ of $1 / 2-\mathrm{in}$. hose and a Hypro ${ }^{\mathrm{TM}}$ long throw gun. Storage room for two drip torches, 5 gallons of drip torch fuel, one metal backpack pump, one gallon of pump engine fuel, and a small tool box is also available in the cargo box area. The equipment filled weight is about $625 \mathrm{lb}$.

The Gator operates easily when placed in either forward or reverse and depressing the foot throttle. This simplicity of operation is important since we have numerous inexperienced students helping on burns. Its mobility during burns and during mop-up has been unparalleled. It is able to travel in areas that our CJ-7 Jeep with a slip-on pump unit cannot traverse. On one burn the Gator traveled down a wooded, pleasure horse trail that was used as a firebreak, with no problems. In 
the past when we had burned the area, it was all done with backpack pumps and hand tools, but now we have access to a slip-on pump unit for wetlines or spotovers. Other added benefits are the ability to go through creeks or wet areas without getting stuck or leaving deep ruts. The balloon-like tires with low pressure cause minimal surface disturbance. The Gator is also fuel-efficient. It has been on burns traveling several miles along the fireline, with the engine running constantly for over four hours and used only half of the 5.3 gal. tank of fuel.

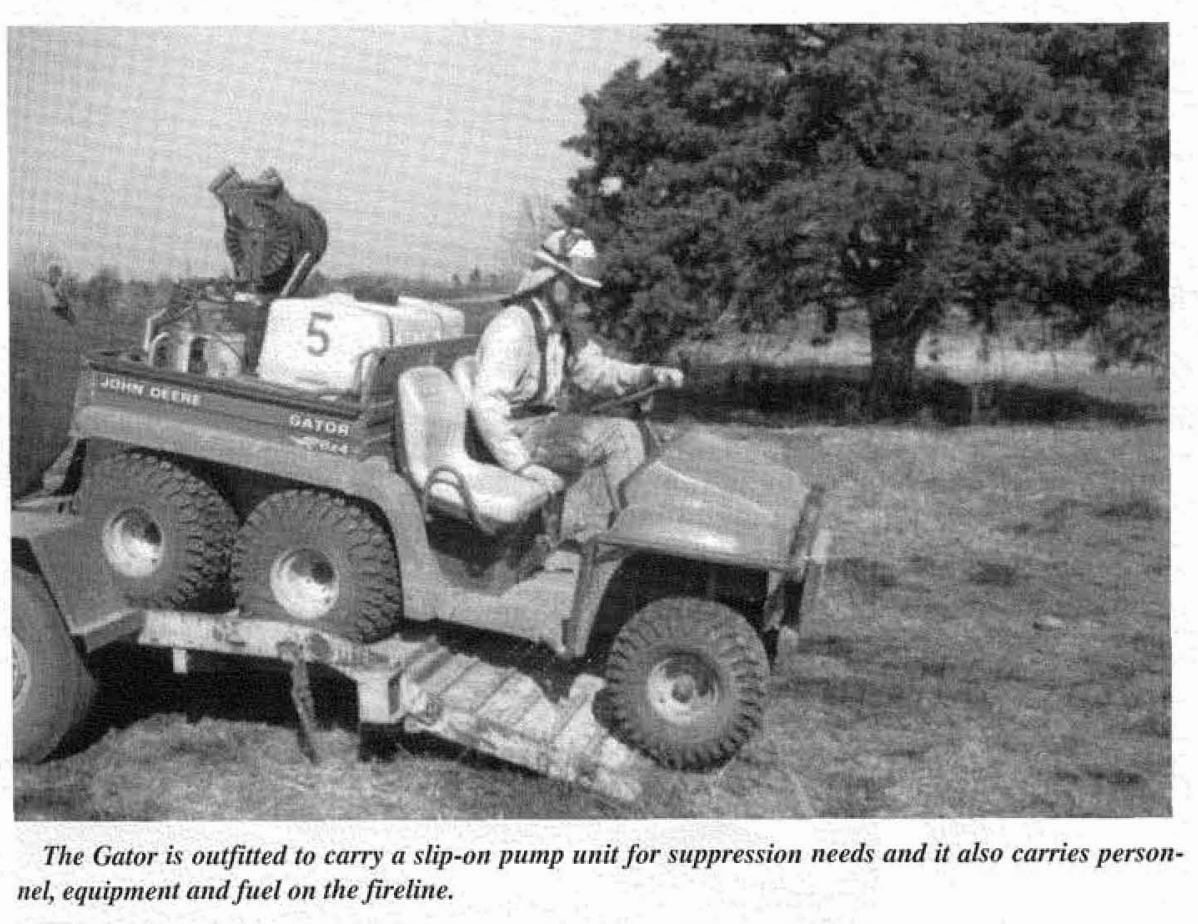

The Gator is outfitted to carry a slip-on pump unit for suppression needs and it also carries personnel, equipment and fuel on the fireline.

We use the Gator in the post-oak and blackjack oak forest, and also in the pine forests of southeastern Oklahoma. In southeastern Oklahoma we encountered narrow firebreaks with numerous seeps and large rocks where a $4 \times 4$ pick-up would have problems operating and maneuvering. The Gator was not hindered and performed well. It decreased our burning time considerably, mainly due to its ability to travel the entire fireline with considerable speed and maneuverability. It also caused minimal surface disturbance on the dry slopes, as well as in the seep areas. It works well also in tallgrass prairie burns. It is able to travel around the fireline rapidly to check for, or respond to spotfires, carry personnel or equipment where needed, or to ignite the headfire.

Traveling to and from burns we haul the Gator with a twin axle, flatbed, bumper-pull trailer, with no problems. The Gator weighs 1,057 lbs. without the pumper unit, which is not too large a load for most standard size pick-ups to pull. The Gator is then loaded on the back of a $16-\mathrm{ft}$. twin axle, flatbed, gooseneck trailer, with a 600 -gal. water tank and pump, with $600-\mathrm{ft}$. of 1 -in. hose. When we get to a burn unit, the

Gator is unloaded for off-road use, and the large water trailer is used on the improved roads.

We have had to adjust the Gator to overcome a minor problem with the steering. With the added weight in the back, the front end was lighter and caused the front tires to slide when turned sharply, thus reducing turn radius. We overcame this by adding a 100 lb. weight to the front brush guard. Another item of concern is the front and back fenders, which are made of plastic and will probably not tolerate too much heat. We have not had any meltdowns yet, but by keeping the drivers informed
The Gator weighs 1,057 lbs. without the pumper unit, which is not too large a load for most standard size pick-ups to pull.

and watching out for excess heat on the fireline, we hope to avoid this problem. The only time the Gator has become immobilized was when it became highcentered on a deeply eroded trail. A few more inches of ground clearance could assist travel, but might also reduce its stability by raising the center of gravity. Care should be taken in driving over large rocks, or well-worn or eroded trails. On the positive side, the Gator's small size allows two or three people to push it off high-center or use a hand operated come-a-long to pull it free.

The Gator has been used on over ten different prescribed burns this year and we have not encountered any significant problems. The Gator has increased our effectiveness in conducting prescribed burns, increased safety along the fireline, and considerably reduced burn times.

John Weir is Superintendent of the OSU Research Range, Division of Agriculture and Natural Resources, Oklahoma State University, Stillwater, Oklahoma. This article is approved for publication by the Director, Oklahoma Agricultural Experiment Station. 